\title{
(2) OPEN ACCESS \\ Outcomes of endotracheal suctioning in non-vigorous neonates born through meconium-stained amniotic fluid: a systematic review and meta-analysis
}

\author{
Nanthida Phattraprayoon, Wimonchat Tangamornsuksan, Teerapat Ungtrakul
}

\begin{abstract}
- Additional material is published online only. To view please visit the journal online (http://dx.doi.org/10.1136/ archdischild-2020-318941).
\end{abstract}

Faculty of Medicine and Public Health, HRH Princess Chulabhorn College of Medical Science, Chulabhorn Royal Academy, Bangkok, Thailand

\section{Correspondence to} Dr Nanthida Phattraprayoon, Faculty of Medicine and Public Health, HRH Princess Chulabhorn College of Medical Science, Chulabhorn Royal Academy, Bangkok, Thailand; nanthida.pha@CRA.ac.th

Received 31 January 2020 Revised 11 May 2020

Accepted 19 May 2020 Published Online First 19 June 2020
Check for updates

(C) Author(s) (or their employer(s)) 2021. Re-use permitted under CC BY-NC. No commercial re-use. See rights and permissions. Published by BMJ.

To cite: Phattraprayoon $\mathrm{N}$ Tangamornsuksan W,

Ungtrakul T. Arch Dis Child

Fetal Neonatal Ed

2021:106:F31-F38.

\section{ABSTRACT}

Objective We aimed to systematically review and analyse the outcomes of non-endotracheal suctioning (non-ETS) versus ETS in non-vigorous meconium-stained neonates.

Design We conducted a systematic review of nonETS and ETS in non-vigorous infants born through meconium-stained amniotic fluid (MSAF). We searched PubMed/Medline, Scopus, Clinical Trials.gov, Cumulative Index to Nursing and Allied Health, and Cochrane Library databases from inception to November 2019, using keywords and related terms. Only non-vigorous infants born through MSAF included in randomised controlled trials, were included. We calculated overall relative risks (RRs) and mean differences with $95 \%$ Cls using a random-effects model, to determine the impact of ETS in non-vigorous infants born through MSAF.

Main outcome measures The primary outcome was the incidence of meconium aspiration syndrome (MAS). Secondary outcomes were respiratory outcome measures (pneumothorax, persistent pulmonary hypertension of the newborn, secondary pneumonia, need for respiratory support, duration of mechanical ventilation), initial resuscitation and others including shock, perinatal asphyxia, convulsions, neonatal mortality, blood culturepositive sepsis and duration of hospital stay.

Results A total of 2085 articles were identified in the initial database search. Four studies, including 581 nonvigorous meconium-stained infants, fulfilled the inclusion criteria, comprising 292 infants in the non-ETS group and 289 in the ETS group. No statistically significant difference was found for MAS (RR 0.98; $95 \% \mathrm{Cl} 0.71$ to 1.35).

Conclusions Initiating ETS soon after birth in nonvigorous meconium-stained infants may not alter their neonatal outcomes.

\section{INTRODUCTION}

Meconium-stained amniotic fluid (MSAF) is a condition in which infants have passed meconium in amniotic fluid. The incidence of MSAF is generally about $5 \%-20 \%$ of all births ${ }^{1-3}$ and increases with advanced gestational age. ${ }^{45}$ MSAF can be a sign of fetal maturity or of a pathological condition, such as an infant with hypoxia. ${ }^{6}$ Hypoxic stress causes colonic activity leading to meconium passage and stimulating fetal gasping movements, which results in meconium aspiration.

MSAF may cause problems including meconium aspiration syndrome (MAS), persistent pulmonary hypertension of the newborn (PPHN) and

\section{What is already known on this topic?}

- Recent data have shown that endotracheal suctioning (ETS) provides no benefit over no ETS (non-ETS) in non-vigorous meconium-stained infants.

- There is no difference in the incidence of meconium aspiration syndrome (MAS) in infants who receive ETS and those who do not.

\section{What this study adds?}

- Our results confirm that there is no difference in for many aspects of the outcomes, including MAS, between ETS versus non-ETS in nonvigorous meconium-stained infants.

- Our results support the practices in the Neonatal Resuscitation Program 2015 guideline.

hypoxic-ischaemic encephalopathy (HIE). ${ }^{7}$ Infants born through MSAF have a higher risk of developing respiratory distress. ${ }^{8}$ The incidence of MAS in meconium-stained infants is approximately $5 \%-10.5 \%$, with a mortality rate of $12 \%$. This incidence has been decreasing over time. ${ }^{910}$ Nevertheless, morbidity associated with MAS varies from mild to severe disease. ${ }^{10-13}$ Severe MAS carries a substantial risk of death and permanent disability. ${ }^{11}$

Many strategies have been applied to reduce complications in infants born through MSAF, such as suctioning meconium from the airway. Unfortunately, studies by Wiswell et al did not find that the intervention of suctioning in vigorous meconiumstained infants led to a decrease in the incidence of MAS. ${ }^{14-16}$ Moreover, the intubation procedure may cause distress and airway injury. ${ }^{17}$ In 2000 , the Neonatal Resuscitation Program (NRP) guidelines suggested mouth and pharynx suctioning of secretions before delivery of the neonate's shoulders, followed by endotracheal suctioning (ETS) only in non-vigorous infants born through MSAF. ${ }^{18} 19$ Since 2006, the NRP guidelines have been adjusted to mouth and tracheal suctioning under direct visualisation, without the need for mouth and pharynx suctioning at the perineum soon after birth in nonvigorous infants born through MSAF. ${ }^{20}{ }^{21}$ Despite having been practised for a decade, ${ }^{22}$ the latest NRP 2015 guidelines no longer suggest routine ETS in non-vigorous infants delivered through MSAF. ${ }^{23}$ 
Nonetheless, the outcomes of this practice remain questionable owing to little evidence using human data. ${ }^{24}$

Thus, we aimed to determine the neonatal outcomes of no ETS (non-ETS) compared with routine ETS in non-vigorous, meconium-stained infants.

\section{Methods}

We performed this systematic review and meta-analysis following the recommendations established by Preferred Reporting Items for Systematic Reviews and Meta-Analyses. We included any non-vigorous infants born through MSAF.

\section{Outcomes}

Our primary outcome was the incidence of MAS. Secondary outcomes were other respiratory outcomes (pneumothorax, PPHN, secondary pneumonia, need for respiratory support), initial resuscitation and others, including shock, perinatal asphyxia, convulsions, neonatal mortality and blood culturepositive sepsis. The durations of hospital stay and mechanical ventilation were also investigated.

\section{Search strategy and selection criteria}

A comprehensive and systematic search was performed from inception until November 2019 using PubMed/Medline, Scopus, Clinical Trials.gov, Cumulative Index to Nursing and Allied Health, and the Cochrane Library, using keywords, synonyms, and other terms related to MSAF and ETS, and with no language restrictions. Only randomised controlled trials (RCTs) and human studies were included. Additional studies were retrieved from the bibliographies of the included articles.

Two reviewers (NP and WT) independently screened the titles and/or abstracts for relevance, followed by full-text article assessment. The inclusion criteria were any non-vigorous neonates born through MSAF included in randomised clinical trials investigating the effects of non-ETS or ETS. For studies with inadequate information for meta-analysis, additional data were sought from the corresponding authors of the selected articles.

\section{Data extraction, bias and quality assessment}

Data were extracted by two reviewers (NP and WT), including study details (study design, year of publication, population and end points), patient characteristics (patient demographics, number of patients, gestational age, sex, and neonatal and maternal parameters), eligibility criteria, method of data collection, definition of outcomes and other outcomes of interest reported by the authors. To evaluate the validity of the eligible randomised trials among the included studies, two reviewers (NP and WT) independently assessed the risk of bias for each study using the revised Cochrane risk-of-bias tool for randomised trials (RoB 2), as recommended by the Cochrane Collaboration. ${ }^{25}$ Any disagreements were resolved through discussion or involvement of a third reviewer (TU).

\section{Data analysis}

Meta-analysis was performed using data for the same outcome in two or more studies. The overall relative risks (RRs) and mean differences with $95 \%$ CIs were calculated to determine the effects of ETS in non-vigorous infants born through MSAF for dichotomous outcomes and continuous outcomes, respectively. For continuous data, if the studies reported median and range or IQR, the data were converted to mean and SD. ${ }^{26}{ }^{27}$ All analyses were carried out using the DerSimonian and Laird method in a random-effects model. ${ }^{28}$ Statistical heterogeneity was assessed

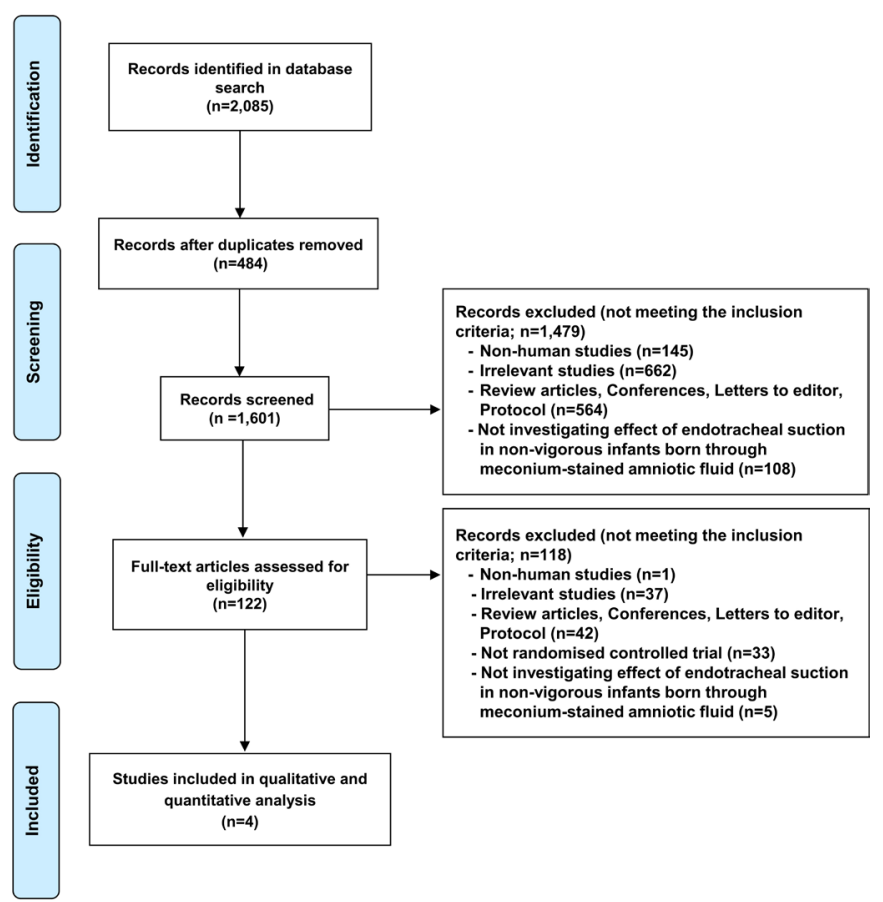

Figure 1 PRISMA (Preferred Reporting Items for Systematic Reviews and Meta-Analyses) flow diagram.

via the Q-statistic and $\mathrm{I}^{2}$ tests. $^{29}{ }^{30}$ Values of $\mathrm{p} \leq 0.05$ indicated heterogeneity between studies, ${ }^{29}$ with $\mathrm{I}^{2}$ values of $25 \%, 50 \%$ and $75 \%$ indicating low, moderate and high levels of heterogeneity across studies, respectively. ${ }^{30}$ All statistical analyses were performed using Stata V.14.0 (StataCorp, College Station, Texas, USA).

\section{RESULTS}

\section{Search strategy and selection criteria}

Our literature search and selection criteria are summarised in figure 1. We identified 2085 articles in the initial database search. After removing duplicate records, 1601 articles were first screened on the basis of title and/or abstract, according to the inclusion criteria. Subsequently, a total 122 full-text articles were screened and 118 were further excluded for the following reasons: (1) Non-human studies (1 article). (2) Non-relevant studies (37 articles). (3) Review articles, case reports, letters to the editor, commentaries, and conference abstracts (42 articles) and non-RCTs (33 articles). (4) No investigation of the effects of ETS in non-vigorous infants born through MSAF (5 articles). Finally, four studies were included for further meta-analysis, ${ }^{31-34}$ with no additional articles identified in the review of bibliographies of the included studies.

\section{Study characteristics, risk of bias and quality assessment}

All investigations were conducted in various locations throughout India, and were completed before the release of the 2015 NRP guidelines. All studies were published between 2015 and 2019. The details of studies and maternal and neonatal characteristics are shown in tables 1 and 2, respectively. Outcomes were categorised according to systematic classification, including resuscitation and neonatal outcomes (table 3 ).

Similar definitions used in most studies and some variables were defined, as below.

1. Non-vigorous: ${ }^{31-34}$ heart rate $<100$ beats per minute (bpm), decreased muscle tone, not breathing/crying or gasping 


\begin{tabular}{|c|c|c|c|c|}
\hline Study & Chettri et al, $2015^{31}$ & Nangia et al, $2016^{32}$ & Kumar et al, $2019^{33}$ & Singh et al, $2019^{34}$ \\
\hline Type of study & RCT & RCT & RCT & RCT \\
\hline Location & Pondicherry, India & New Delhi, India & Varanasi, India & Lucknow, India \\
\hline Inclusion criteria & $\begin{array}{l}\text { Term neonate } \\
\text { (GA } \geq 37 \text { weeks) } \\
\text { MSAF } \\
\text { Non-vigorous }\end{array}$ & $\begin{array}{l}\text { Term neonate } \\
\text { (GA 37-41 weeks) } \\
\text { - Cephalic presentation } \\
\text { Singleton } \\
\text { MSAF } \\
\text { - Non-vigorous }\end{array}$ & $\begin{array}{l}\text { Late preterm and term neonate } \\
(\mathrm{GA} \geq 34 \text { weeks) } \\
\text { MSAF } \\
\text { Non-vigorous }\end{array}$ & $\begin{array}{l}\text { Late preterm and term neonate } \\
(\mathrm{GA} \geq 34 \text { weeks) } \\
\text { MSAF } \\
\text { Non-vigorous }\end{array}$ \\
\hline Exclusion criteria & $\begin{array}{l}\text { Major congenital anomalies } \\
\text { No consent }\end{array}$ & $\begin{array}{l}\text { Major congenital malformation } \\
\text { Refusal to participate }\end{array}$ & $\begin{array}{l}\text { Major congenital anomalies } \\
\text { Maternal chorioamnionitis } \\
\text { No consent }\end{array}$ & $\begin{array}{l}- \text { Major congenital } \\
\text { malformation } \\
- \text { No consent }\end{array}$ \\
\hline Study period & February 2013 to July 2014 & May 2012 to August 2013 & January 2014 to September 2015 & September 2011 to August 2012 \\
\hline Resuscitators & $\begin{array}{l}\text { One paediatric resident trained in } \\
\text { neonatal resuscitation }\end{array}$ & Not reported & $\begin{array}{l}\text { Two paediatric residents trained in } \\
\text { neonatal resuscitation }\end{array}$ & $\begin{array}{l}\text { At least two paediatric residents } \\
\text { trained in neonatal resuscitation }\end{array}$ \\
\hline Time to non-vigorous assessment & At 5-10s after birth & At birth & At birth & At $5-10$ s after birth \\
\hline Procedures & $\begin{array}{l}\text { Intubated with endotracheal } \\
\text { suctioning immediately after } \\
\text { birth }\end{array}$ & $\begin{array}{l}\text { Oropharyngeal suctioning then } \\
\text { intubated with endotracheal } \\
\text { suctioning }\end{array}$ & $\begin{array}{l}\text { Oropharyngeal suctioning then } \\
\text { intubated with endotracheal } \\
\text { suctioning }\end{array}$ & $\begin{array}{l}\text { Intubated with endotracheal } \\
\text { suctioning immediately after } \\
\text { birth }\end{array}$ \\
\hline $\begin{array}{l}\text { Number of times endotracheal } \\
\text { suctioning performed }\end{array}$ & Maximum of 2 times & Not reported & Generally, 2-3 times & Maximum of 2 times \\
\hline
\end{tabular}

GA, gestational age; MSAF, meconium-stained amniotic fluid.

2. Fetal distress: ${ }^{31-34}$ category III fetal heart rate (absent baseline fetal heart rate tracing with recurrent late decelerations, or recurrent variable decelerations or bradycardia and sinusoidal pattern)

3. Meconium consistency ${ }^{31}$ thin: watery-consistency fluid; moderate: opaque fluid without particles; and thick: peasoup consistency or opaque fluid containing particulate material

4. Respiratory problems:

- MAS: $:^{31-34}$ neonates with respiratory distress of unexplained origin on chest X-ray and symptoms owing to other diseases (radiographic findings: diffuse, asymmetrical patchy infiltrates with hyperinflation, or segmental or lobular atelectasis)

- Severity of MAS: ${ }^{33}$ Cleary and Wiswell Score

- Severity of respiratory distress: ${ }^{32}$ Downes Score

- PPHN: $:^{34}$ labile hypoxaemia (peripheral capillary oxygen saturation $<90 \%$ and/or arterial partial pressure of oxygen $\left(\mathrm{PaO}_{2}\right)<50 \mathrm{~mm} \mathrm{Hg}$ ) with preductal and postductal oxygen saturation difference of $>10 \%$ or $\mathrm{PaO}_{2}$ difference of $>20 \mathrm{~mm} \mathrm{Hg}$, with/without echocardiography confirmation

- Transient tachypnoea of the newborn: ${ }^{33}$ respiratory distress with normal or perihilar, streaky markings as radiographic features

5. Perinatal asphyxia: ${ }^{31}$ Apgar Score $\leq 6$ at 5 min after birth with cord blood $\mathrm{pH}<7$ and a base deficit of $>12$, and $\mathrm{HIE}^{32}$ as assessed by Levene's stages

6. Severity of shock: ${ }^{31}$ : Wernovsky Score.

7. Obstetric problems

- Prolonged labour: ${ }^{34}$ failure to progress with labour lasting $\geq 20$ hours and $\geq 14$ hours in primiparous and multiparous women, respectively

- Obstructed labour: ${ }^{34}$ presenting part of the fetus cannot progress into the birth canal, despite strong uterine contractions

- Premature rupture of membranes: ${ }^{34}$ rupture of membranes before the onset of labour

- Prolonged rupture of membranes: ${ }^{34}$ rupture of membranes $>24$ hours before delivery
It should be noted that there were some concerns about risk of bias assessment based on the RoB 2 tool in all included studies (online supplementary file 1).

\section{Study and patient characteristics}

A summary of all data and patient characteristics of the included studies, which were matched between the groups, is shown in tables 1 and 2.

\section{Outcome of the analyses}

A total of 581 non-vigorous infants was recruited in this study. Of these, 292 were in the non-ETS group and 289 were in the ETS group. The evidence of heterogeneity and tests for overall effects are detailed in figure 2 . In our comparison, $R R>1$ indicated that the risk of acquiring illness or disease was greater in the non-ETS group and $\mathrm{RR}<1$ indicated that the risk of acquiring illness or disease was lower in the non-ETS group (table 3 ).

\section{Outcomes of respiratory system}

MAS

In four studies, ${ }^{31-34}$ MAS was diagnosed in 201/581 (35\%) infants; non-ETS=101/292 (35\%) and ETS=100/289 (35\%), with no significant difference in the incidence of MAS between non-ETS and ETS groups at birth: RR 0.98 ; 95\% CI $(0.71$ to 1.35).

Other respiratory outcomes, such as pneumothorax, PPHN and secondary pneumonia were not indicated as statistically significant effects of ETS at birth. Results regarding the need for respiratory support, including mechanical ventilation or even mechanical ventilation alone, were similar. Kumar et $a l^{33}$ also reported results for pulmonary haemorrhage.

Outcomes of other systems, including cardiovascular system, neurological system infection and neonatal mortality

The overall outcomes with respect to other systems exhibited that non-ETS would not result in a higher risk of these complications. Cardiovascular problems, such as shock, neurological outcomes like perinatal asphyxia/HIE or convulsions, were not significantly different, as compared with the other group. 
Table 2 Maternal and neonatal characteristics

\begin{tabular}{|c|c|c|c|c|c|c|c|c|}
\hline \multirow[b]{2}{*}{ Characteristics } & \multicolumn{2}{|c|}{ Chettri et al, $2015^{31}$} & \multicolumn{2}{|c|}{ Nangia et al, $2016^{32}$} & \multicolumn{2}{|c|}{ Kumar et al, $2019^{33}$} & \multicolumn{2}{|c|}{ Singh et al, $2019^{34}$} \\
\hline & Non-ETS=61 & $\mathrm{ETS}=61$ & Non-ETS $=88$ & $\mathrm{ETS}=87$ & Non-ETS $=66$ & $\mathrm{ETS}=66$ & Non-ETS=77 & $\mathrm{ETS}=75$ \\
\hline Maternal age (years), mean $\pm S D$ & $25.2 \pm 4.8$ & $24.3 \pm 4.5$ & NR & & $25.2 \pm 4.0$ & $26.4 \pm 4.5$ & $26.6 \pm 3.7$ & $27.1 \pm 3.6$ \\
\hline \multicolumn{9}{|l|}{ Mode of delivery } \\
\hline SVD, n (\%) & $9(15)$ & $13(21)$ & NR & & $17(26)$ & $8(12)$ & $18(23)$ & $26(35)$ \\
\hline Caesarean/low segment C-section, n (\%) & $30(49)$ & $29(48)$ & $37(42)$ & $34(39)$ & $49(74)$ & $57(86)$ & $30(39)$ & $30(40)$ \\
\hline \multicolumn{9}{|l|}{ Gravida } \\
\hline Gravida ( $\leq 2$ nd gravida), $\mathrm{n}(\%)$ & NR & & $66(75)$ & $65(75)$ & NR & & NR & \\
\hline Multigravida, n (\%) & NR & & NR & & NR & & $38(49)$ & $33(44)$ \\
\hline \multicolumn{9}{|l|}{ Antenatal care } \\
\hline Antenatally registered, $\mathrm{n}(\%)$ & NR & & $49(56)$ & $58(67)$ & NR & & NR & \\
\hline Antenatal care ( $\geq 3$ visits), $n(\%)$ & NR & & NR & & $23(35)$ & $24(36)$ & NR & \\
\hline Antenatal care ( $\geq 4$ visits), $n(\%)$ & NR & & NR & & NR & & $57(74)$ & $49(65)$ \\
\hline \multicolumn{9}{|l|}{ Maternal risk factors } \\
\hline $\begin{array}{l}\text { Maternal risk factors I anaemia; } \mathrm{Hb} \\
<10.5 \mathrm{~g} / \mathrm{dL}), \mathrm{n}(\%)\left({ }^{*} \mathrm{Hb}<10 \mathrm{~g} / \mathrm{dL}\right)\end{array}$ & $18(30)$ & $17(28)$ & NR & & NR & & $9(12)^{\#}$ & $12(16)^{\#}$ \\
\hline $\begin{array}{l}\text { Maternal risk factors II } \\
\text { (PIH, pre-eclampsia, eclampsia), }\end{array}$ & $6(10)$ & $9(15)$ & Included in oth & risk factors & $15(23)$ & $13(20)$ & $19(25)$ & $23(31)$ \\
\hline $\begin{array}{l}\text { Other maternal risk factors III } \\
{ }^{2}(\mathrm{PIH}, \mathrm{HT}, \mathrm{GDM}, \text { renal diseases/ } \\
\text { oligohydramnios/ cardiovascular disease), } \\
\mathrm{n}(\%) \\
{ }^{\mathrm{G}} \mathrm{GDM} \text { on insulin, hypothyroid, rheumatic } \\
\text { heart disease }\end{array}$ & $3(5)^{\pi}$ & $3(5)^{\pi}$ & $15(17)^{\lambda}$ & $22(25)^{\lambda}$ & NR & & $3(4)^{\pi}$ & $2(3)^{\pi}$ \\
\hline Oligohydramnios, n (\%) & $6(10)$ & $8(13)$ & NR & & $6(9)$ & $7(11)$ & $1(1)$ & $2(3)$ \\
\hline Premature rupture of membranes, $\mathrm{n}(\%)$ & $10(16)$ & $11(18)$ & NR & & NR & & $23(30)$ & $19(25)$ \\
\hline Prolonged rupture of membranes, $\mathrm{n}(\%)$ & NR & & NR & & NR & & $13(17)$ & $13(17)$ \\
\hline Thick meconium, n (\%) & $39(64)$ & $42(69)$ & $69(78)$ & $61(70)$ & $30(45)$ & $28(42)$ & $47(61)$ & $47(63)$ \\
\hline \multicolumn{9}{|l|}{ Neonatal characteristics } \\
\hline Male, n (\%) & $36(59)$ & $33(54)$ & $52(59)$ & $52(60)$ & $29(44)$ & $35(53)$ & $43(56)$ & $40(53)$ \\
\hline Birth weight $(\mathrm{g})$, mean $\pm \mathrm{SD}$ & $2900 \pm 350$ & $2870 \pm 490$ & $2763 \pm 533$ & $2649 \pm 437$ & $2528 \pm 598$ & $2620 \pm 696$ & $2461 \pm 192$ & $2462 \pm 315$ \\
\hline 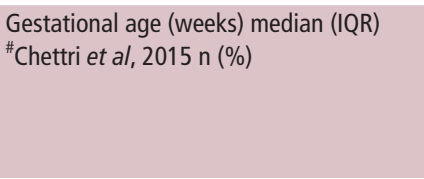 & $\begin{array}{l}37-41^{6 / 7} \text { weeks } \\
57(93)^{\#} \\
\geq 42 \text { weeks } \\
4(7)^{\#}\end{array}$ & $\begin{array}{l}37- \\
41^{6 / 7} \text { weeks } \\
55(90)^{\#} \\
\geq 42 \text { weeks } \\
6(10)^{\#}\end{array}$ & $39(37-40)$ & $39(37-40)$ & $38(36-40)$ & $38(36-40)$ & $38.56 \pm 2.0$ & $38.57 \pm 2.2$ \\
\hline Apgar Score at $1 \mathrm{~min} \leq 3, \mathrm{n}(\%)$ & $36(59)$ & $37(61)$ & $22(25)$ & $18(21)$ & $27(41)$ & $33(50)$ & $25(32)$ & $29(39)$ \\
\hline Apgar Score at $5 \mathrm{~min} \leq 3, \mathrm{n}(\%)$ & $2(3)$ & $2(3)$ & NR & NR & $4(6)$ & $3(5)$ & $0(0)$ & $1(1)$ \\
\hline Apgar Score at $5 \mathrm{~min}<7, \mathrm{n}(\%)$ & $27(44)$ & $30(49)$ & $13(15)$ & $16(18)$ & $15(23)$ & $13(20)$ & $26(34)$ & $30(40)$ \\
\hline Cord blood pH & $6.90 \pm 0.32$ & $6.92 \pm 0.36$ & $7.14 \pm 0.13$ & $7.13 \pm 0.14$ & NR & NR & $7.09 \pm 0.11$ & $7.08 \pm 0.11$ \\
\hline Cord blood base deficit & $14 \pm 6.28$ & $15 \pm 7.84$ & $8.23 \pm 6.19$ & $8.06 \pm 5.78$ & NR & NR & $15.77 \pm 3.13$ & $15.86 \pm 3.22$ \\
\hline
\end{tabular}

All values are reported as frequency (\%), unless otherwise noted.

ETS, endotracheal suctioning; GDM, gestational diabetes mellitus; Hb, haemoglobin; $\mathrm{HT}$, hypertension; Non-ETS, no endotracheal suctioning; NR, not reported; PIH, pregnancyinduced hypertension; SD, standard deviation; SVD, normal spontaneous vaginal delivery.

Chettri et $a l^{31}$ reported the results of mental and motor development delay according to the Differential Ability Scales, Second Edition for Indian infants whereas intracranial haemorrhage was demonstrated in the study by Kumar et al. ${ }^{33}$

Both neonatal mortality and blood culture-positive sepsis were demonstrated in the same direction. ETS did not affect these outcomes.

Kumar et $a l^{33}$ also reported the results of gastrointestinal bleeding, acute kidney injury, thrombocytopenia, abnormal glucose level and electrolyte imbalance.

\section{Outcomes regarding the need for initial resuscitation}

Positive pressure ventilation, chest compression and epinephrine use during resuscitation were not different between groups. On the whole, the results in the non-ETS group were not significantly different for initial resuscitation needed over the ETS group.
Duration of mechanical ventilation (hours) and hospital stay (days)

Both durations of mechanical ventilation and hospital stay were not decreased with ETS at birth.

\section{DISCUSSION}

This was a systematic review and meta-analysis regarding nonETS and ETS in meconium-stained infants, following release of NRP 2015. Our study comprised four RCTs between 2011 and 2015 conducted in different parts of India according to the NRP 2010 guideline. These four RCTs were published between 2015 and 2020, to provide further information and precisely determine whether non-ETS or ETS could benefit these infants. In total, 581 non-vigorous meconium-stained infants were eligible for the study and were classified as belonging to either the nonETS (292 infants) or ETS (289 infants) groups. Our systematic 


\section{Original research}

Table 3 Outcomes by system

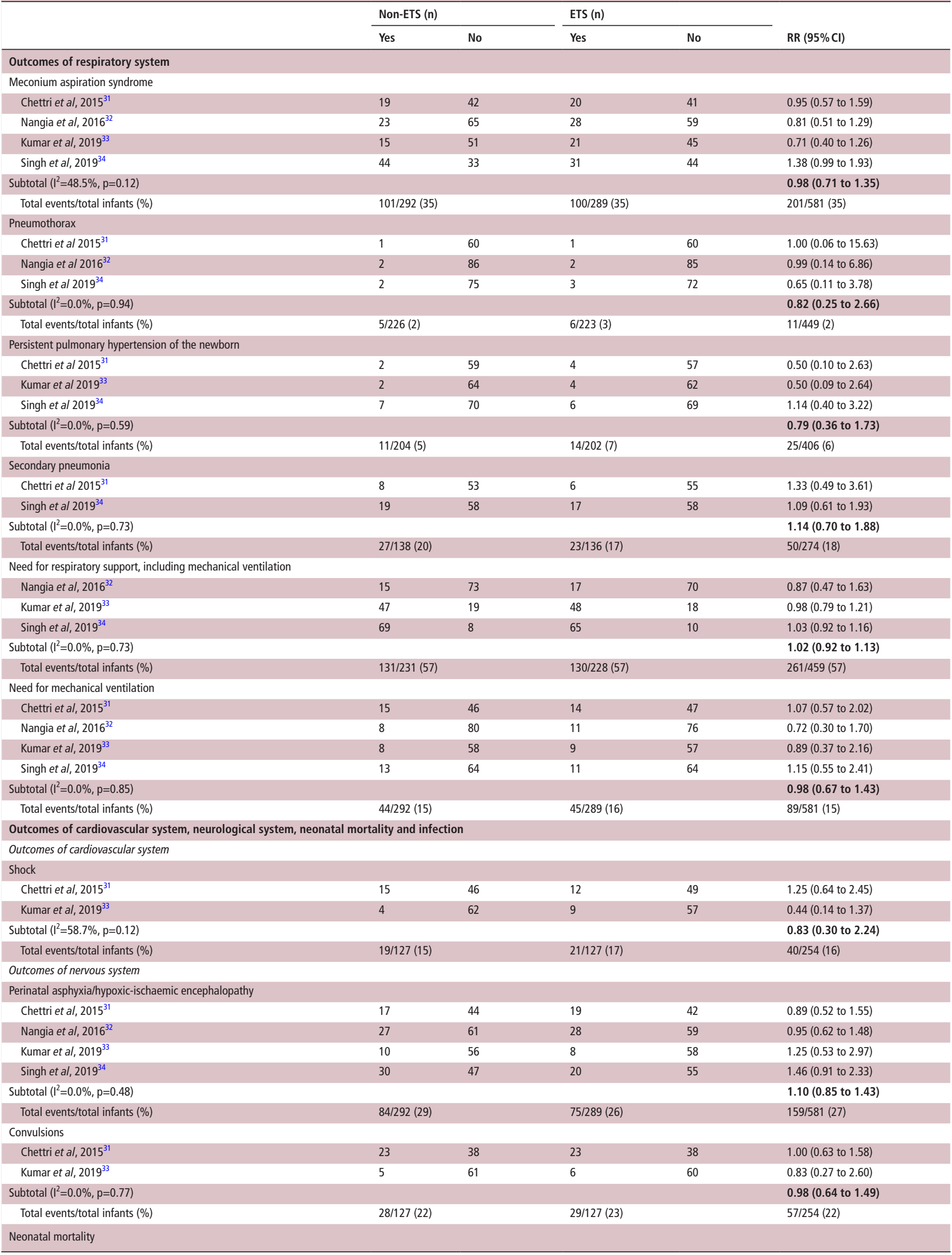

Continued 
Original research

Table 3 Continued

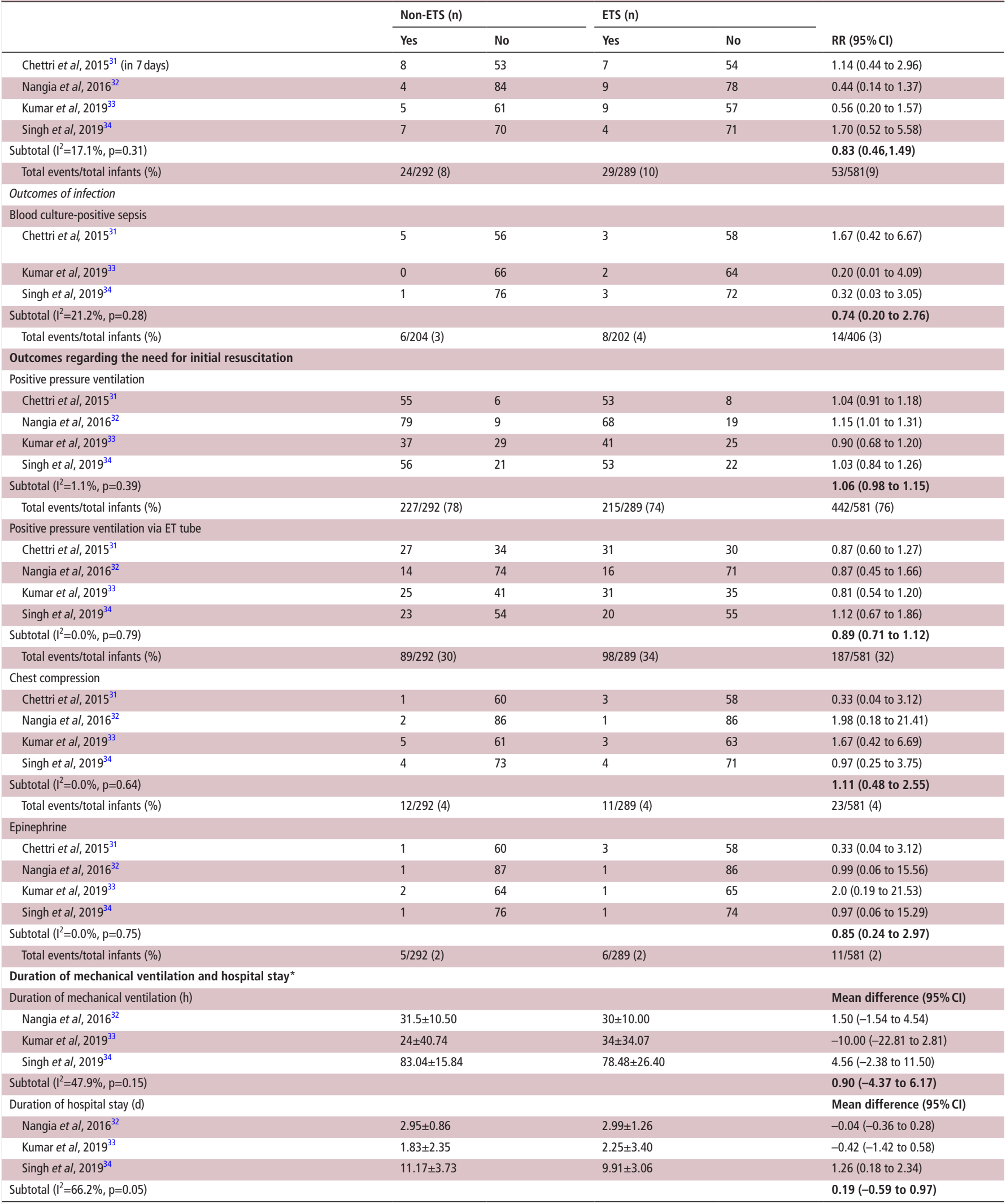

$\mathrm{RR}>1$ indicated that the risk of acquiring illness or disease was greater in the non-ETS group and RR $<1$ indicated that the risk of acquiring illness or disease was lower in the non-ETS group

*The data were converted from median and range or IQR to mean and SD.

$\mathrm{Cl}$, confidence interval; ETS, endotracheal suctioning; RR, relative risk.

review and meta-analysis yielded no increasing incidence of MAS, which was the primary outcome. Overall, our study showed that neonatal outcomes with respect to respiratory, cardiovascular and neurological systems; neonatal mortality; blood culturepositive sepsis; and the need for initial resuscitation; including the durations of mechanical ventilation and hospital stay, were 
A)

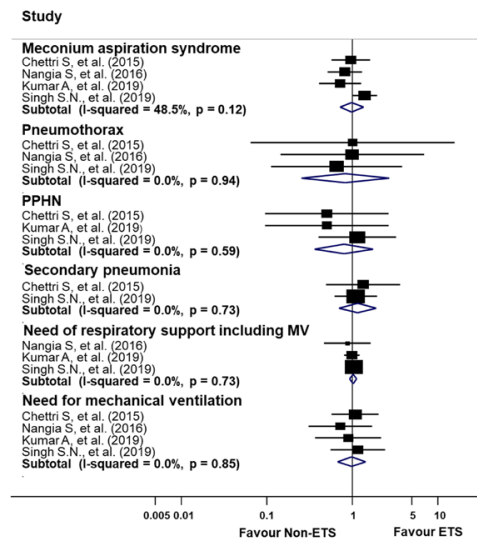

Relative Risks
$(95 \% \mathrm{Cl})$

B)

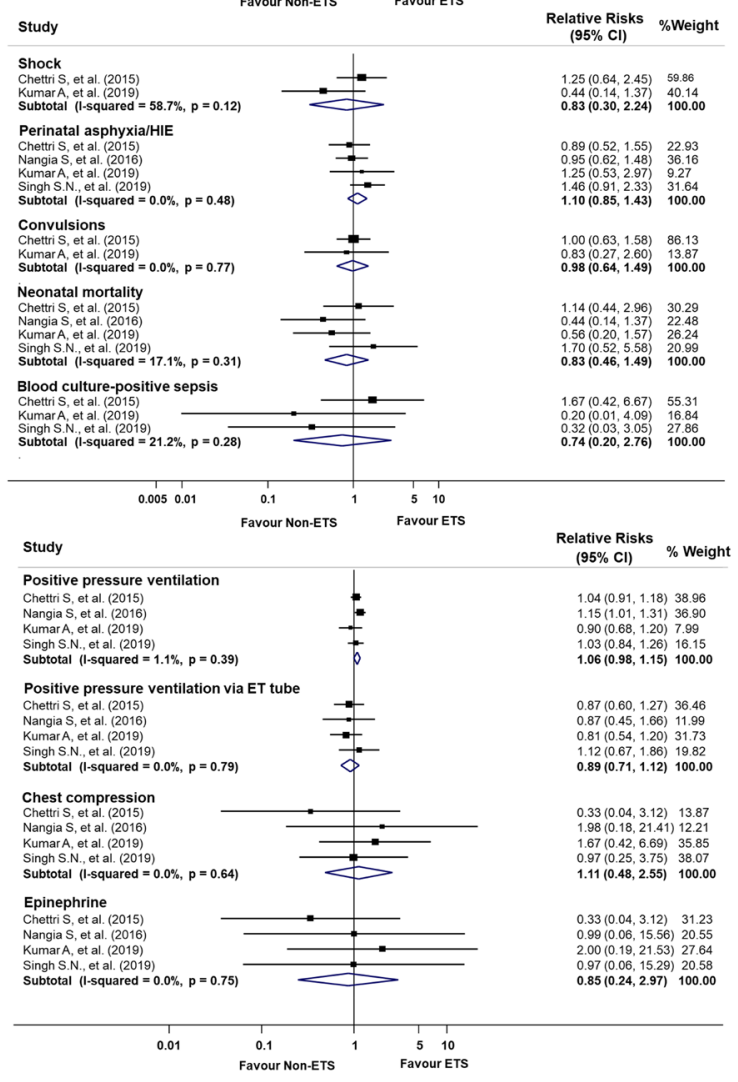

D)

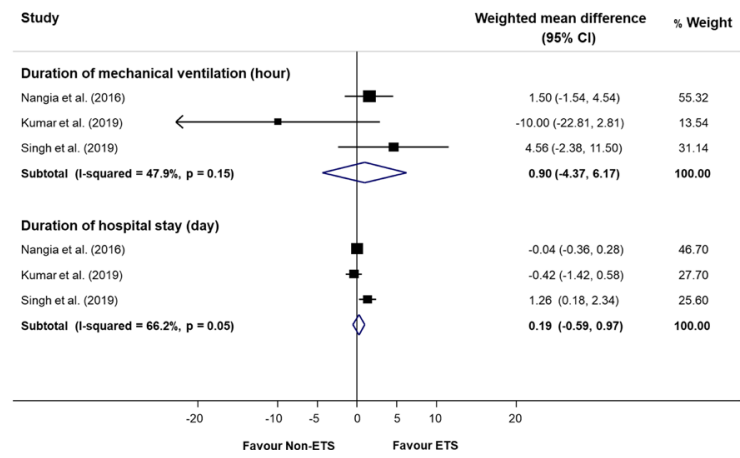

Figure 2 Forest plots of meta-analysis for neonatal outcomes of non-endotracheal suctioning compared with endotracheal suctioning in non-vigorous neonates born through meconium-stained amniotic fluid. (A) Outcomes of respiratory system. B) Outcomes of cardiovascular system, nervous system, neonatal mortality and infection. C) Outcomes regarding the need for initial resuscitation. D) Duration of mechanical ventilation and hospital stay. ETS, endotracheal suctioning; HIE, hypoxicischaemic encephalopathy; PPHN, persistent pulmonary hypertension of the newborn; MV, mechanical ventilation comparable between the non-ETS and ETS groups. Therefore, our systematic review and meta-analysis supported the use of the NRP 2015 guidelines for non-routine ETS in non-vigorous infants born through MSAF.

Recently, Chiruvolu et $a l^{35}$ revealed an increase in neonatal intensive care unit admission for respiratory problems, mechanical ventilation, oxygen use and surfactant therapy in nonvigorous, meconium-stained infants using the latest NRP. The limitation of observational study design with uncontrollable confounding variables in this study may contribute to the distinction.

The inclusion of RCTs was the strength of this study, though some limitations remain. First, differences were noted in details of the included studies, such as time to non-vigorous assessment, oropharyngeal suctioning before ETS, with a possible indirect infant stimulation and the diversity of non-vigorous infant's clinical characters, which may have an impact on the outcomes. Chettri $e a^{31}$ and Singh $e t a l^{34}$ assessed infants as vigorous or non-vigorous within $5-10 \mathrm{~s}$ of birth. Whereas, Nangia et $a l^{32}$ evaluated infants immediately at birth, similarly to Kumar et al. ${ }^{33}$ Oropharyngeal suctioning was performed before ETS in two studies. ${ }^{32} 33$ Furthermore, the proportion of neonates who had Apgar Score $<7$ at 5 min or acidaemia (cord blood $\mathrm{pH} \leq 7.2$ ) was high in some studies, ${ }^{3134}$ which may represent potentially sicker non-vigorous neonates. Second, there were insufficient data on the complications of intubation. Lastly, the interventions in all studies were undertaken by one or two trained providers in each centre, based in India. Thus, the findings may not be generalisable to other healthcare settings or more experienced providers.

Importantly, one of the most worrisome factors among paediatricians regarding the practice of ETS in non-vigorous meconium-stained infants is the delayed resuscitation because neonates may lose the opportunity to undergo a timely and effective resuscitation process. Although ETS is not routinely administered in non-vigorous meconium-stained neonates according to the NRP 2015 guidelines, if meconium blockage is suspected, resuscitators can perform ETS with a meconium aspirator. ${ }^{23}$

According to the aforementioned data, the lack of comprehensive data may contribute to higher heterogeneity in some aspects of the results. A large, appropriately powered and designed RCT should be further established to determine the best practice for non-vigorous meconium-stained neonates.

While working on our study, Trevisanuto et al reported on the tracheal suctioning of meconium at birth for non-vigorous infants; their findings demonstrated insufficient evidence to suggest immediate routine direct laryngoscopy for tracheal suctioning, ${ }^{36}$ of which the results were concordant with our study.

In conclusion, our systematic review and meta-analysis of RCTs on the resuscitation of non-vigorous meconium-stained infants yielded no difference in the outcomes of neonates receiving or not receiving ETS.

Contributors All authors had full access to all of the data in this study and take responsibility for the integrity of the data and the accuracy of the data analysis.Study concept and design: NP and WT. Acquisition, analysis and interpretation of data: NP, WT and TU. Drafting of the manuscript: NP, WT and TU. Critical revision of the manuscript for important intellectual content: NP. Statistical analysis, study supervision: WT. Reviewed and approved the final manuscript to be submitted: NP, WT and TU.

Funding The authors have not declared a specific grant for this research from any funding agency in the public, commercial or not-for-profit sectors.

Competing interests None declared.

Patient consent for publication Not required.

Provenance and peer review Not commissioned; externally peer reviewed. 
Data availability statement All data relevant to the study are included in the article or uploaded as supplementary information. All data may be published.

Open access This is an open access article distributed in accordance with the Creative Commons Attribution Non Commercial (CC BY-NC 4.0) license, which permits others to distribute, remix, adapt, build upon this work non-commercially, and license their derivative works on different terms, provided the original work is properly cited, appropriate credit is given, any changes made indicated, and the use is non-commercial. See: http://creativecommons.org/licenses/by-nc/4.0/.

\section{REFERENCES}

1 Romero R, Yoon $\mathrm{BH}$, Chaemsaithong $\mathrm{P}$, et al. Bacteria and endotoxin in meconiumstained amniotic fluid at term: could intra-amniotic infection cause meconium passage? J Matern Fetal Neonatal Med 2014;27:775-88.

2 Mitchell S, Chandraharan E. Meconium-stained amniotic fluid. Obstet Gynaecol Reprod Med 2018;28:120-4.

3 Paz Levy D, Walfisch A, Wainstock T, et al. Meconium-stained amniotic fluid exposure is associated with a lower incidence of offspring long-term infectious morbidity. Am J Reprod Immunol 2019;81:e13108.

4 Rawat M, Nangia S, Chandrasekharan P, et al. Approach to infants born through meconium stained amniotic fluid: evolution based on evidence? Am J Perinatol 2018;35:815-22.

5 Oyelese $Y$, Culin A, Ananth CV, et al. Meconium-stained amniotic fluid across gestation and neonatal acid-base status. Obstet Gynecol 2006;108:345-9.

6 Yurdakök M. Meconium aspiration syndrome: do we know? Turk J Pediatr 2011;53:121-9.

7 Poggi SH, Ghidini A. Pathophysiology of meconium passage into the amniotic fluid. Early Hum Dev 2009;85:607-10.

8 Crowley MA. Neonatal respiratory disorders. In: Martin RJ, Fanaroff AA, Walsh MC, eds. Fanaroff and Martin's Neonatal-Perinatal medicine: diseases of the fetus and infant. Philadelphia: Elsevier Saunders, 2020: 1203-30.

9 Joseph K, UdayKiran G, Reddy DR, et al. Incidence of meconium aspiration syndrome and associated risk factors in babies born to mothers with meconium stained amniotic fluid. Int J Contemp Med Res 2017;4:1457-61.

10 Dargaville PA, Copnell B. Australian and New Zealand neonatal network. The epidemiology of meconium aspiration syndrome: incidence, risk factors, therapies, and outcome. Pediatrics 2006;117:1712-21.

11 Thornton PD, Campbell RT, Mogos MF, et al. Meconium aspiration syndrome: incidence and outcomes using discharge data. Early Hum Dev 2019;136:21-6.

12 Choi W, Jeong H, Choi S-J, et al. Risk factors differentiating mild/moderate from severe meconium aspiration syndrome in meconium-stained neonates. Obstet Gyneco/ Sci 2015;58:24-31.

13 Vain NE, Batton DG. Meconium "aspiration" (or respiratory distress associated with meconium-stained amniotic fluid?). Semin Fetal Neonatal Med 2017;22:214-9.

14 Kabbur PM, Herson VC, Zaremba S, et al. Have the year 2000 neonatal resuscitation program guidelines changed the delivery room management or outcome of meconium-stained infants? J Perinatol 2005;25:694-7.

15 Wiswell TE, Gannon CM, Jacob J, et al. Delivery room management of the apparently vigorous meconium-stained neonate: results of the multicenter, international collaborative trial. Pediatrics 2000;105:1-7.

16 Halliday HL, Sweet DG. Endotracheal intubation at birth for preventing morbidity and mortality in vigorous, meconium-stained infants born at term. Cochrane Database Syst Rev 2001;1:CD000500.
17 Khatami SF, Parvaresh P, Behjati S. Common complications of endotracheal intubation in newborns. Iran I Neonatol 2011:2:12-17.

18 Bhat R, Vidyasagar D. Delivery room management of meconium-stained infant. Clin Perinatol 2012:39:817-31.

19 Niermeyer S, Kattwinkel J, Van Reempts P, et al. International guidelines for neonatal resuscitation: an excerpt from the guidelines 2000 for cardiopulmonary resuscitation and emergency cardiovascular care: international consensus on science. contributors and reviewers for the neonatal resuscitation guidelines. Pediatrics 2000;106:E29.

20 Kattwinkel J. Neonatal resuscitation guidelines for ILCOR and NRP: evaluating the evidence and developing a consensus. J Perinatol 2008;28:S27-9.

21 American Heart Association, American Academy of Pediatrics. 2005 American heart association (AHA) guidelines for cardiopulmonary resuscitation (CPR) and emergency cardiovascular care (ECC) of pediatric and neonatal patients: neonatal resuscitation guidelines. Pediatrics 2006;117:e1029-38.

22 Perlman JM, Wyllie J, Kattwinkel J, et al. Part 11: neonatal resuscitation: 2010 international consensus on cardiopulmonary resuscitation and emergency cardiovascular care science with treatment recommendations. Circulation 2010;122:S516-38

23 Wyckoff MH, Aziz K, Escobedo MB, et al. Part 13: neonatal resuscitation: 2015 American heart association guidelines update for cardiopulmonary resuscitation and emergency cardiovascular care. Circulation 2015;132:S543-60.

24 Wiswell TE. Appropriate management of the nonvigorous meconium-stained neonate: an unanswered question. Pediatrics 2018;142:1-3.

25 Sterne JAC, Savović J, Page MJ, et al. Rob 2: a revised tool for assessing risk of bias in randomised trials. BMJ 2019;366:14898

26 Hozo SP, Djulbegovic B, Hozo I. Estimating the mean and variance from the median, range, and the size of a sample. BMC Med Res Methodol 2005;5:13.

27 Higgins JPT, Green S, eds. Cochrane Handbook for Systematic Reviews of Interventions. Chichester (UK): John Wiley \& Sons, 2008

28 DerSimonian R, Laird N. Meta-Analysis in clinical trials. Control Clin Trials 1986;7:177-88.

29 Higgins JPT, Thompson SG, Deeks JJ, et al. Measuring inconsistency in meta-analyses. BMJ 2003;327:557-60

30 Higgins JPT, Thompson SG. Quantifying heterogeneity in a meta-analysis. Stat Med 2002;21:1539-58.

31 Chettri S, Adhisivam B, Bhat BV. Endotracheal suction for Nonvigorous neonates born through meconium stained amniotic fluid: a randomized controlled trial. J Pediatr 2015;166:1208-13.

32 Nangia S, Sunder S, Biswas R, et al. Endotracheal suction in term non vigorous meconium stained neonates-A pilot study. Resuscitation 2016;105:79-84.

33 Kumar A, Kumar P, Basu S. Endotracheal suctioning for prevention of meconium aspiration syndrome: a randomized controlled trial. Eur J Pediatr 2019;178:1825-32.

34 Singh SN, Saxena S, Bhriguvanshi A, et al. Effect of endotracheal suctioning just after birth in non-vigorous infants born through meconium stained amniotic fluid: a randomized controlled trial. Clin Epidemiol Glob Health 2019;7:165-70.

35 Chiruvolu A, Miklis KK, Chen E, et al. Delivery room management of meconiumstained newborns and respiratory support. Pediatrics 2018;142:e20181485.

36 Trevisanuto D, Strand ML, Kawakami MD, et al. International liaison Committee on resuscitation neonatal life support Task force. tracheal suctioning of meconium at birth for non-vigorous infants: a systematic review and meta-analysis. Resuscitation 2020;149:117-26. 